\title{
Sistem Pendukung Keputusan Penentuan Kesesuaian Lahan Tanaman Cengkeh Dengan Metode Profile Matching
}

\author{
Dessy Sarah Simbolon ${ }^{1 *}$, Bosker Sinaga ${ }^{2}$ \\ ${ }^{1.2}$ STMIK Pelita Nusantara \\ Jl. Iskandar Muda No. 1 Medan 20154 Indonesia \\ Corresponding author‘s e-mail: dessysarah23@gmail.com
}

\begin{abstract}
Abstrak - Tanaman cengkeh merupakan salah satu jenis tanaman rempah yang memiliki banyak manfaat. Bagian yang sering dimanfaatkan dari tanaman cengkeh adalah bagian kuncup bunganya. Biasanya akan melalui proses pengeringan terlebih dahulu sebelum akhirnya dikonsumsi atau digunakan. Metode yang digunakan untuk penentuan kesesuaian lahan tanaman cengkeh adalah metode profile matching. Data-data yang digunakan dalam penentuan kesesuaian lahan tanaman cengkeh didapatkan dengan teknik observasi dan wawancara terhadap karyawan pada alamat Desa Kuta Galuh Kecamatan Tiga Ndreget Kabupaten Karo. Sistem untuk penentuan kesesuaian lahan tanaman cengkeh dibangun dengan menggunakan bahasa pemrograman berbasis web dan database MySQL. Tujuan penelitian menentukan kesesuaian lahan tanaman cengkeh Pada Kecamatan Tiga Ndreget Kabupaten Karo.Perhitungan penentuan ranking Hasil Akhir dari proses profile matching adalah ranking. Penentuan ranking mengacu pada hasil perhitungan tertentu. Hasil perhitungan metode profile matching antara lain Desa Kuta Galuh Nilai Akhir 5.02 Rangking 1, Desa Nari Gunung Nilai Akhir 4,98 Rangking 2, Desa Tanjung Belang Nilai Akhir 4,56 Rangking 3.
\end{abstract}

Kata kunci: Kecocokan Lahan, SPK, Gap, Ranking, Profile Matching

Abstract - Clove is a type of spice plant that has many benefits. The part that is often used from the clove plant is the flower bud. Usually it will go through a drying process before it is finally consumed or used. The method used to determine land suitability for clove plants is the profile matching method. The data used in determining the suitability of land for clove plants was obtained by using observation and interviews with employees at the address of Kuta Galuh Village, Tiga Ndreget District, Karo Regency. The system for determining land suitability for clove plants was built using a web-based programming language and MySQL database. The purpose of this study was to determine the suitability of land for clove plants in Tiga Ndreget District, Karo Regency. Calculation of ranking determination The final result of the profile matching process is ranking. Determination of ranking refers to the results of certain calculations. The results of the calculation of the profile matching method include Kuta Galuh Village with a Final Score of 5.02 Ranking 1, Nari Gunung Village with a Final Score of 4.98 Ranking 2, Tanjung Belang Village with a Final Score of 4.56 Ranking 3. Keywords: Land Suitability, SPK, Gap, Ranking, Profile Matching

\section{Pendahuluan}

Cengkeh adalah rempah-rempah purba kala yang telah dikenal dan digunakan ribuan tahun sebelum masehi, dan merupakan tanaman perkebunan/industri berupa pohon dengan Family Myrtaceae. Kuncup bunga dari tanaman inilah yang sering kali disebut oleh masyarakat sebagai cengkeh [1]. Cengkeh biasa digunakan sebagai penambah cita rasa makanan maupun minuman. Sensasinya yang hangat dan pedas cukup digemari oleh kalangan masyarakat, terutama yang tinggal di daerah dingin. Di samping itu, cengkeh juga memiliki manfaat yang baik untuk kesehatan tubuh karena diketahui mengandung fosfor, zat besi, magnesium, kalsium, kalium, seng, natrium, dan vitamin. Untuk tata cara menanam cengkeh agar berbuah lebat, tidak terlepas dari pengolahan lahan yang baik. Pengolahan lahan sebaiknya dilakukan dua bulan sebelum melakukan proses pemindahan bibit. Memang butuh waktu yang sedikit lebih lama guna menunggu lahan agar siap untuk ditanami. Untuk ketinggian cengkeh yaitu 2-2,5 meter, untuk total produksi nya sekitar 15.00 ton /tahun .suhu udara 24-270C dan curah hujan 60-80 mm/bulan atau 2000-3500 mm/tahun. Oleh karena itu petani sangat sulit untuk membudayakan tanaman cengkeh oleh sebab itu harus di kembangkan supaya tidak punah dengan cara menentukan lahan yang sesuai untuk penanaman tanaman cengkeh.

Keputusan merupakan rangkaian tindakan yang perlu diikuti dalam memecahkan masalah untuk menghindari atau mengurangi dampak negatif atau untuk memanfaatkan kesempatan [2]. Sistem pendukung keputusan (SPK) biasanya dibangun untuk mendukung solusi atas suatu masalah atau untuk suatu peluang. Penelitian Sistem Pendukung Keputusan Pemilihan Mahasiswa Berprestasi dengan Metode Profile Matching (Studi Kasus: Fakultas Teknik UNTAN) menguraikan SPK yang dibangun dari beberapa penelitian dalam pemecahan masalahnya memerlukan suatu metode pendekatan dalam pengambilan keputusan, salah satunya adalah metode Profile Matching. Profile matching atau pencocokan profil adalah metode yang sering dipakai sebagai mekanisme dalam pengambilan keputusan dengan mengasumsikan bahwa terdapat tingkat variabel prediktor yang ideal yang harus dipenuhi oleh subyek yang diteliti, bukannya tingkat minimal yang harus dipenuhi atau dilewati [3]. Penelitian Penerapan Metode Profile Matching dalam Penentuan Jenis Tanaman menguraikan Profile Matching merupakan salah satu metode yang dapat membantu dalam memaksimalkan 
hasil pertanian, karena metode ini mengasumsikan bahwa terdapat tingkat variabel prediktor ideal yang harus dipenuhi oleh subyek yang harus dipenuhi, bukannya tingkat minimal yang harus dipenuhi atau dilewati. Penelitian ini bertujuan untuk mengetahui bibit tanaman terbaik untuk sistem pertanian aquaponic yang ditentukan dari metode profile matching. Penelitian Sistem Pendukung Keputusan Pemilihan Kategori Promosi Produk Menggunakan Metode Profile Matching (Studi Kasus : Minimarket) menjelaskan Peran sebuah sistem pendukung keputusan dalam membantu menyelesaikan masalah-masalah yang tidak terstruktur telah banyak diterapkan, agar bisnis yang sedang dikelola bisa terus bertahan dan bersaing dibidangnya maka pengambilan keputusan terhadap sebuah promosi produk harus dilakukan tepat sasaran [4]. Penelitian Sistem Pendukung Keputusan Untuk Kenaikan Jabatan Menggunakan Metode Profile Matching Modeling menerangkan Profile matching merupakan suatu proses yang sangat penting dalam manajemen SDM, terlebih dahulu ditentukan kompetensi (kemampuan) yang diperlukan oleh suatu jabatan. Kompetensi/kemampuan tersebut haruslah dapat dipenuhi oleh pemegang/calon pemegang jabatan [5].

\section{Tinjauan Pustaka}

\subsection{Sistem Pendukung Keputusan}

Sistem Pendukung Keputusan mengacu pada suatu sistem yang memanfaatkan dukungan komputer dalam proses pengambilan keputusan [6]. Hal ini dikemukakan oleh beberapa ahli, diantaranya Little Man dan Watson memberi definisi bahwa Sistem Pendukung Keputusan merupakan suatu sistem yang interaktif, yang membantu pengambil keputusan melalui penggunaan data dan model-model keputusan untuk memecahkan masalah-masalah yang sifatnya semi terstruktur dan tidak terstruktur Sistem Pendukung Keputusan (SPK) dirancang untuk mendukung seluruh yang relevan, menentukan pendekatan yang digunakan dalam pengambilan keputusan, sampai mengevaluasi pemilihan interaktif [7]. Peranan sistem pendukung keputusan dalam konteks keseluruhan sistem informasi ditujukan untuk memperbaiki kinerja melalui aplikasi teknologi informasi [8].

\subsection{Metode Profile Matching}

Metode Profile Matching merupakan salah satu metode sistem pendukung keputusan dengan mengasumsikan bahwa terdapt tingkat variable prediktor yang ideal yang harus dipenuhi oleh subyek yang diteliti, bukannya tingkat minimal yang harus dipenuhi atau dilewati [9]. Metode profile matching sangat penting dalam manajemen Sumber Daya Manusia (SDM) dimana terlebih dahulu ditentukan kompetensi (kemampuan) yang dibutuhkan [10]. Metode profile matching atau pencocokan profil adalah metode yang sering digunakan sebagai mekanisme dalam pengambilan keputusan dengan mengasumsikan bahwa terdapat tingkat variabel prediktor yang ideal yang harus dipenuhi oleh subyek yang diteliti, bukannya tingkat minimal yang harus dipenuhi atau dilewati [11]. GAP adalah perbedaan antara profile yang dimiliki oleh masingmasing alternatif dengan profile standar [12] [13].

\section{Metode Penelitian}

Pada bagian ini kerangka kerja penelitian yang sudah disusun dijelaskan seusai kebutuhan. Berikut adalah uraian kerangka kerja yang dilakukan penelitian ini yang disertai dengan penjelasan:

a. Identifikasi Masalah

Sebagai bagian dari proses penelitian dapat dipahami sebagai upaya mendefinisikan problem dan membuat definisi tersebut dapat diukur (measurable) sebagai langkah awal penelitian. Pada tahap ini identifikasi masalah bagian dari proses penelitian yang dapat dipahami sebagai suatu upayauntuk mendefinisikan masalah yang ada dan membuat permasalahan tersebut dapat diukur dan diuji dan proses untuk menentukan apa saja yang menjadi bagian inti dari sebuah penelitian.

b. Merumuskan Masalah

Rumusan yang menanyakan suatu kejadian atau fenomena yang ada, baik itu kedudukannya mandiri, atau pun kejadian atau fenomena yang saling berkaitan antara satu dengan yang lainnya. Rumusan masalah mempertanyakan beberapa hal yang berkaitan dengan suatu penelitian, dimana nantinya jawaban dari pertanyaan inilah yang akan menjadi hasil penelitian itu. Permasalahan dalam kasus ini adalah kurangnya pengetahuan petani dalam memilih lahan cengkeh yang baik.

c. Pengumpulan Data

Proses mengumpulkan dan mengukur informasi tentang variabel yang ditargetkan dalam sistem yang mapan, yang kemudian memungkinkan seseorang untuk menjawab pertanyaan yang relevan dan mengevaluasi hasil. Dalam melakukan penyajian data tepat dan terukur ini memerlukan data-data yang akurat. Pengumpulan data pada kasus ini dilakukan dengan metode observasi dan wawancara kepada pemilik tanaman cengkeh.

d. Data Dengan Metode Profile Matching

Proses analisa metode Profile Matching dengan membandingkan GAP antara nilai alternatif dan kriteria GAP dimana selisih antara nilai alternatif dan kriteria, semakin kecil GAP yang dihasilkan maka bobot nilainya semakin besar yang berarti memiliki peluang lebih besar. 
e. Perancangan Sistem

Pada tahap ini merupakan tahap menggambarkan secara rinci bagaimana sistem akan berjalan. Bertujuan untuk menghasilkan produk perangkat lunak yang sesuai dengan kebutuhan user dalam menentukan kesesuaian lahan tanaman cengkeh.

f. Pembangunan Sistem

Hal ini merupakan proses membangun sistem sesuai kebutuhan yang telah dirancang berbagai prinsip dan teknik untuk tujuan-tujuan pendefinisian suatu perangkat, proses, atau sistem hingga tingkat detil tertentu yang memungkinkan realisasi bentuk fisiknya dan yang berhubungan dengan proses analisis dan desain sistem.

g. Pengujian Sistem

Pada tahap ini merupakan tahap pengujian program perangkat lunak yang lengkap dan terintegrasi. Hal itu bertujuan untuk melakukan pengecekan apakah berhail tidaknya perangkat lunak sesuai dengan kebutuhan user dalam menentukan kesesuaian lahan tanaman cengkeh.

h. Penyusunan Laporan

Hal ini merupakan proses kegiatan penting dalam suatu sistem informasi di setiap organisasi yaitu menyusun laporan kegiatan penelitian yang dilakukan.

i. Publikasi Ilmiah

Hal ini merupakan publikasi pada jurnal ilmiah yang diterbitkan sesuai ketentuan standar pihak kampus yang telah ditentukan.

\section{Hasil dan Pembahasan}

Sistem pendukung keputusan dalam penentuan kesesuaian lahan tanaman cengkeh yaitu dengan menggunakan metode Profile Matching. Metode Profile Matching merupakan salah satu metode yang sederhana dalam system pendukung keputusan dengan membandingkan GAP antara nilai alternatif dan kriteria. GAP merupakan proses membandingkan nilai aspek standar kompetensi awal dengan kompetensi masukan yang nantinya akan dirangking berdasarkan nilai tertinggi. nilai GAP merupakan nilai kompetensi sesuai yang dibutuhkan. Semakin kecil nilai GAP yang dihasilkan maka bobot nilainya semakin besar yang berarti memiliki peluang lebih besar untuk pemilihan yang sesuai.

Tabel 1. Bobot Nilai GAP

\begin{tabular}{|c|c|c|l|}
\hline No & Selisih (GAP) & Nilai Bobot $\left(\mathrm{W}_{\mathrm{j}}\right)$ & \multicolumn{1}{|c|}{ Keterangan } \\
\hline 1 & 0 & 6 & Tidak ada GAP (Kompetensi sesuai yang dibutuhkan) \\
\hline 2 & 1 & 5,5 & Kompetensi individu kelebihan 1 tingkat/level) \\
\hline 3 & -1 & 5 & Kompetensi individu kekurangan 1 tingkat/level) \\
\hline 4 & 2 & 4,5 & Kompetensi individu kelebihan 2 tingkat/level) \\
\hline 5 & -2 & 4 & Kompetensi individu kekurangan 2 tingkat/level) \\
\hline 6 & 3 & 3,5 & Kompetensi individu kelebihan 3 tingkat/level) \\
\hline 7 & -3 & 3 & Kompetensi individu kekurangan 3 tingkat/level) \\
\hline 8 & 4 & 2,5 & Kompetensi individu kelebihan 4 tingkat/level) \\
\hline 9 & -4 & 2 & Kompetensi individu kekurangan 4 tingkat/level) \\
\hline 10 & 5 & 1,5 & Kompetensi individu kelebihan 5 tingkat/level) \\
\hline 11 & -5 & 1 & Kompetensi individu kekurangan 5 tingkat/level) \\
\hline
\end{tabular}

Tabel 2. Nilai Asumsi Bobot Profile Matching

\begin{tabular}{|c|c|c|}
\hline No & Keterangan Bobot & Nilai Bobot \\
\hline 1 & Sangat Sesuai & 5 \\
\hline 2 & Sesuai & 4 \\
\hline 3 & Cukup Sesuai & 3 \\
\hline 4 & Tidak Sesuai & 2 \\
\hline 5 & Sangat Tidak Sesuai & 1 \\
\hline
\end{tabular}

Keterangan :

Nilai bobot asumsi metode Profile Matching atau pembobotan pada metode Profile Matching terdapat antara range 0 -5 berdasarkan skala prioritas masing- masing kriteria.

Tabel 3. Pembagian Kriteria

\begin{tabular}{|c|c|c|}
\hline No & \multicolumn{1}{|c|}{ Kriteria } & \multicolumn{1}{c|}{ Sub Kriteria } \\
\hline \multirow{3}{*}{1} & \multirow{2}{*}{ Klasifikasi Tanah(C1) } & $\mathrm{pH}$ Tanah $(\mathrm{C} 1.1)$ \\
\cline { 3 - 3 } & & Jenis Tanah $(\mathrm{C} 1.2)$ \\
\hline
\end{tabular}




\begin{tabular}{|l|l|l|}
\cline { 3 - 3 } 2 & Kondisi Lahan (C2) & Ketembapan Udara (C1.3) \\
\cline { 3 - 3 } & & Intensitas Cahaya (C2.2) \\
\hline \multirow{2}{*}{3} & \multirow{2}{*}{ Iklim (C3) } & Suhu Udara (C3.1) \\
\cline { 3 - 3 } & & Curah Hujan Tahunan (C3.2) \\
\hline
\end{tabular}

Tabel 4. Sub Kriteria Ph Tanah (C1.1)

\begin{tabular}{|c|c|c|}
\hline No & Ph Tanah & Keterangan \\
\hline 1 & $\mathrm{Ph} \mathrm{6-7}$ & Sangat Sesuai \\
\hline 2 & $\mathrm{Ph} 8-9$ & Sesuai \\
\hline 3 & $\mathrm{Ph} 3-5$ & Cukup Sesuai \\
\hline 4 & $\mathrm{Ph} 1-2$ & Tidak Sesuai \\
\hline 5 & $\mathrm{Ph} 10-14$ & Sangat Tidak Sesuai \\
\hline
\end{tabular}

Tabel 5. Sub Kriteria Jenis Tanah (C1.2)

\begin{tabular}{|c|c|c|}
\hline No & Jenis Tanah & Keterangan \\
\hline 1 & Tanah Humus & Sangat Sesuai \\
\hline 2 & Tanah Andosol & Sesuai \\
\hline 3 & Tanah Alluvial & Cukup Sesuai \\
\hline 4 & Tanah Entisol & Tidak Sesuai \\
\hline 5 & Tanah Enseptol & Sangat Tidak Sesuai \\
\hline
\end{tabular}

Tabel 6. Sub Kriteria Kelembapan Udara (C1.3)

\begin{tabular}{|c|c|c|}
\hline No & KelembapanUdara & Keterangan \\
\hline 1 & $83-88 \%$ & Sangat Sesuai \\
\hline 2 & $79-82 \%$ & Sesuai \\
\hline 3 & $89-92 \%$ & Cukup Sesuai \\
\hline 4 & $0,1-79 \%$ & Tidak Sesuai \\
\hline 5 & $93-99 \%$ & Sangat Tidak Sesuai \\
\hline
\end{tabular}

Tabel 7. Sub Kriteria Ketinggian Tempat (C2.1)

\begin{tabular}{|l|c|c|}
\hline No & Ketinggian Tempat & Keterangan \\
\hline 1 & $1.200-1.400 \mathrm{mdp}$ & Sangat Sesuai \\
\hline 2 & $1.100-1.200 \mathrm{mdpl}$ & Sesuai \\
\hline 3 & $1.500-1.800 \mathrm{mdpl}$ & Cukup Sesuai \\
\hline 4 & $0-1.000 \mathrm{mdpl}$ & Tidak Sesuai \\
\hline 5 & $>1.800 \mathrm{mdpl}$ & Sangat Tidak Sesuai \\
\hline
\end{tabular}

Tabel 8. Sub Kriteria Intensitas Cahaya (C2.2)

\begin{tabular}{|c|c|c|}
\hline No & Intensitas Cahaya & Keterangan \\
\hline 1 & $1700-2000$ & Sangat Sesuai \\
\hline 2 & $1.300-1.600$ & Sesuai \\
\hline 3 & $2.100-1.500$ & Cukup Sesuai \\
\hline 4 & $2.100-1.500$ & Tidak Sesuai \\
\hline 5 & $0-700$ & Sangat Tidak Sesuai \\
\hline
\end{tabular}

Tabel 9. Sub Kriteria Suhu Udara (C3.1)

\begin{tabular}{|c|c|c|}
\hline No & Suhu Udara & Keterangan \\
\hline 1 & $15^{\circ} \mathrm{C}-18^{\circ} \mathrm{C}$ & Sangat Sesuai \\
\hline 2 & $10^{\circ} \mathrm{C}-14^{\circ} \mathrm{C}$ & Sesuai \\
\hline 3 & $19^{\circ} \mathrm{C}-24^{\circ} \mathrm{C}$ & Cukup Sesuai \\
\hline 4 & $0{ }^{\circ} \mathrm{C}-9^{\circ} \mathrm{C}$ & Tidak Sesuai \\
\hline 5 & $<25^{\circ} \mathrm{C}$ & Sangat Tidak Sesuai \\
\hline
\end{tabular}

Tabel 10. Sub Kriteria Curah Hujan Tahunan (C3.2)

\begin{tabular}{|c|c|c|}
\hline No & Curah Hujan & Keterangan \\
\hline 1 & $200-900 \mathrm{~mm} / \mathrm{th}$ & Sangat Sesuai \\
\hline 2 & $1.000-1.500 \mathrm{~mm} / \mathrm{th}$ & Sesuai \\
\hline
\end{tabular}




\begin{tabular}{|c|c|c|}
\hline 3 & $0-190 \mathrm{~mm} / \mathrm{th}$ & Cukup Sesuai \\
\hline 4 & $1.600-2.100 \mathrm{~mm} / \mathrm{th}$ & Tidak Sesuai \\
\hline 5 & $<2.100 \mathrm{~mm} / \mathrm{th}$ & Sangat Tidak Sesuai \\
\hline
\end{tabular}

Contoh kasus : Data karakteristik lahan di Kecamatan Tiga Nderket Kabupaten Karo pada tabel 11 akan dihitung kesesuaian lahannya terhadap tanaman cengkeh denganmenggunakan metode profile matching.

Tabel 11. Karakteristik Lahan di Kecamatan Tiga Nderket Kabupaten Karo

\begin{tabular}{|l|c|c|c|}
\hline \multicolumn{1}{|c|}{ Nama Sub Kriteria } & Desa Kuta Galuh & Desa Tanjung Belang & Desa Nari Gunung \\
\hline pH tanah (C1.1) & 6 & 5 & 6 \\
\hline Jenis tanah (C1.2) & Humus & Humus & Humus \\
\hline Kelembapanudara(C1.3) & $79 \%$ & $90 \%$ & $84 \%$ \\
\hline Ketinggiantempat (C2.1) & 1000 & 2000 & 3000 \\
\hline Intensitas cahaya (C2.2) & 1700 & 1800 & 1600 \\
\hline Suhu udara (C3.1) & $25^{\circ} \mathrm{c}-28^{0} \mathrm{c}$ & $25^{\circ} \mathrm{c}-28^{0} \mathrm{c}$ & $25^{0} \mathrm{c}-28^{0} \mathrm{c}$ \\
\hline Curah hujan (C3.2) & $160 \mathrm{~mm} / \mathrm{thn}$ & $170 \mathrm{~mm} / \mathrm{thn}$ & $180 \mathrm{~mm} / \mathrm{thn}$ \\
\hline
\end{tabular}

Berikut merupakan perhitungan nilai total kriteria Klasifikasi Tanah, Kondisi Lahan dan Kriteria Iklim dengan nilai persentasi yang telah ditetapkan.

1. Kriteria Klasifikasi Tanah( Core Factor)

Desa Kuta Galuh (A1) $=50 \%(6)+30 \%(55)=4,65$

Desa tanjung belang (A2) $=50 \%(4)+30 \%(6)=3,8$

Desa nari gunung (A3) $=50 \%(6)+30 \%(6)=4,8$

2. Kriteria Kondisi Lahan

Desa kuta galuh (A1) $\quad=60 \%(4)+40 \%(6)=4,8$

Desa tanjung belang (A2) $=60 \%(4)+40 \%(6)=4,8$

Desa nari gunung $(\mathrm{A} 3)=60 \%(4)+40 \%(6)=4,8$

3. Kriteria Iklim

Desa kuta galuh $(\mathrm{A} 1) \quad=70 \%(3)+30 \%(4)=3,3$

Desa tanjung belang (A2) $=70 \%(3)+30 \%(4)=3,3$

Desa nari gunung (A3) $=70 \%(3)+30 \%(4)=3,3$ 
Tabel 12. Hasil Perhitungan Nilai Total

\begin{tabular}{|c|c|c|c|c|c|c|c|}
\hline \multirow[t]{2}{*}{ Alternatif } & \multicolumn{3}{|c|}{ Klasifikasi Tanah } & \multicolumn{2}{|c|}{ Kondisi Lahan } & \multicolumn{2}{|c|}{$\begin{array}{l}\mathrm{Ik} \\
\mathrm{li} \\
\mathrm{m}\end{array}$} \\
\hline & Ph Tanah & $\begin{array}{r}\text { Jenis } \\
\text { Tanah }\end{array}$ & $\begin{array}{c}\text { Kelembapan } \\
\text { Udara }\end{array}$ & $\begin{array}{c}\text { Ketinggian } \\
\text { Tempat }\end{array}$ & $\begin{array}{c}\text { Intentsitas } \\
\text { Cahaya }\end{array}$ & $\begin{array}{l}\mathrm{Su} \\
\mathrm{hu} \\
\mathrm{Ud} \\
\mathrm{ara} \\
\end{array}$ & $\begin{array}{c}\text { Curah } \\
\text { Hujan } \\
\text { Tahunan }\end{array}$ \\
\hline $\begin{array}{c}\mathrm{A} \\
1\end{array}$ & 6 & $\begin{array}{l}5 \\
5\end{array}$ & 4 & 6 & 3 & 4 & 4 \\
\hline $\begin{array}{l}\mathrm{A} \\
2 \\
\end{array}$ & 4 & 6 & 4 & 6 & 3 & 4 & 4 \\
\hline $\begin{array}{l}\mathrm{A} \\
3\end{array}$ & 6 & 6 & 4 & 6 & 3 & 4 & 4 \\
\hline $\begin{array}{l}\mathrm{X} \\
\%\end{array}$ & 50 & $\begin{array}{l}2 \\
0\end{array}$ & 30 & 60 & 40 & 70 & 30 \\
\hline $\begin{array}{l}\mathrm{A} \\
1\end{array}$ & & , & & & $\begin{array}{l}4 \\
8\end{array}$ & & \\
\hline $\begin{array}{l}\mathrm{A} \\
2\end{array}$ & & $\begin{array}{l}3 \\
8\end{array}$ & & & $\begin{array}{l}4 \\
8\end{array}$ & & \\
\hline $\begin{array}{l}\mathrm{A} \\
3\end{array}$ & & $\begin{array}{l}4 \\
8\end{array}$ & & & $\begin{array}{l}4 \\
8\end{array}$ & & \\
\hline
\end{tabular}

Implementasi sistem yang dihasilkan :

a. Halaman Utama

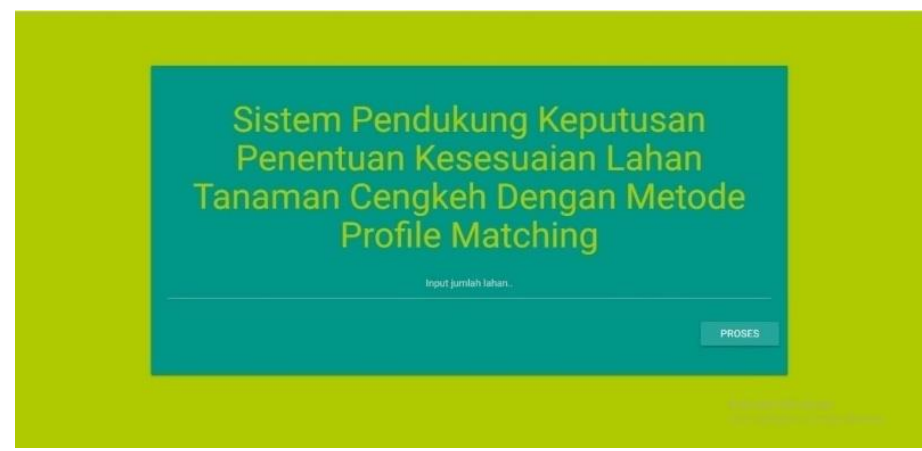

Gambar 1. Halaman Utama

b. Halaman Perhitungan

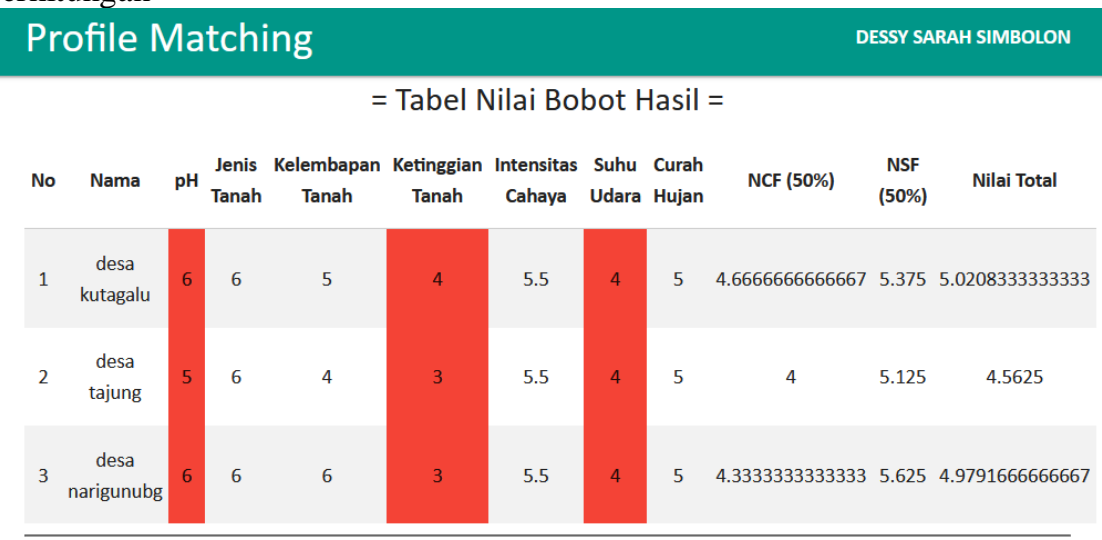

\section{Kesimpulan}

Gambar 2. Halaman Perhitungan

Kesimpulan dari penelitian :

1. Pengolahan data yang didapatkan dari tiga desa kecamatan Tiga Nderket kabupaten Karo untuk menentukan lahan cengkeh yang baik diperoleh hasil ranking, dimana lahan yang paling bagus untuk ditanamnya tanaman cengkeh adalah Desa Kuta Galuh dan Desa Nari Gunung yang berada pada posisi ranking pertama. 
Selanjutnya disusul Desa Tanjung Belang yang cukup bagus untuk penanaman cengkeh yang dapat dijadikan sebagai alternatif kedua yang berada pada posisi rangkin kedua.

2. Sistem Pendukung Keputusan Penentuan Kesesuaian Lahan Tanaman cengkeh menggunakan metode Profile Matching dengan 3 desa altenatif memiliki nilai akhir kesesuaian ada yang sama dan berbeda dimana desa A1 (Desa Kuta Galuh) dan A3 (Desa Nari Gunung) merupakan desa tertinggi dengan nilai akhir 0,39. Sedangkan desa A2 (Desa Tanjung Belang) memiliki yang sedikit lebih rendah dari 2 desa sebelumnya yaitu bernilai 0,36. Sehingga dapat disimpulkan bahwa desa A1 (Desa Kuta Galuh) dan A3 (Desa Nari Gunung) yang memiliki ranking 1 adalah desa yang lahannya paling cocok untuk penanaman tanaman cengkeh daripada desa A2 (Desa Tanjung Belang).

\section{Daftar Pustaka}

[1] F. R. Tulungen, "Cengkeh Dan Manfaatnya Bagi Kesehatan Manusia Melalui Pendekatan Competitive Intelligence," Biofarmasetikal Trop., vol. $\quad 2, \quad$ no. $\quad 2, \quad$ pp. $\quad 158-169$, 2019,https://journal.fmipaukit.ac.id/index.php/jbt/article/view/128.

[2] J. Fitriana, E. F. Ripanti, and T. Tursina, "Sistem Pendukung Keputusan Pemilihan Mahasiswa Berprestasi dengan Metode Profile Matching," J. Sist. dan Teknol. Inf., vol. 6, no. 4, p. 153, 2018, doi: 10.26418/justin.v6i4.27113.

[3] M. B. Structures, "Penerimaan Karyawan Baru Menggunakan Metode Profile Matching," pp. 50-58.

[4] A. Q. Adyan, B. Susilo, and D. Andreswari, "Menggunakan Metode Pembobotan Rank Order Centroid Dan Metode Profile Matching ( Studi Kasus : Smkn 1 Kota Bengkulu ),” J. Rekursif, vol. 8, no. 1, pp. 11-22, 2020.

[5] E. Pawan, W. W. Widianto, and P. Hasan, "Implementasi Metode Profile Matching Untuk Menentukan Penerima Beasiswa Bidikmisi," Creat. Inf. Technol. J., vol. 8, no. 1, p. 54, 2021, doi: 10.24076/citec.2021v8i1.257.

[6] A. S. R. Sinaga and M. Sitorus, "Penerapan Teknik Workshop Pada Pembuatan Blog Bagi Pemula Di Sma Al Washliyah 12 Perbaungan," SELAPARANG J. Pengabdi. Masy. Berkemajuan, vol. 2, no. 2, p. 14, 2019, doi: $10.31764 / j p m b . v 2 \mathrm{i} 2.880$.

[7] M. A. Budhi and N. N. U. Januhari, "Penerapan Metode Profile Matching dalam Penentuan Jenis Tanaman," J. Sist. dan Inform., vol. 13, no. 2, pp. 46-51, 2019.

[8] D. A. Satrio and L. Suryadi, "Sistem Penunjang Keputusan Pada BNI Life Insurance Mengunakan Metode Profile Matching Berbasis Object Oriented," Indones. J. Inf. Syst., vol. 3, no. 1, pp. 532-538, 2020.

[9] S. Arjon, "PEMANFAAATAN IT DALAM PELAKSANAAN UJIAN BERBASIS KOMPUTER PADA SMA NEGERI 2 PERBAUNGAN,” ABDIMASYA J. Pengabdi. pada Masy., vol. 1, no. 1, pp. 1-9, 2020.

[10] A. S. R. Sinaga, M. Marbun, and A. S. Sitio, "Penerapan Teknologi Informasi Penentuan Prioritas Penerima Bantuan Langsung Tunai (BLT) desa Pagar Jati," Jurdimas (Jurnal Pengabdi. Kpd. Masyarakat) R., vol. 4, no. 1, pp. 65-70, 2021, doi: 10.33330/jurdimas.v4i1.681.

[11] B. Triandi, P. Matching, and P. Keputusan, "Jabatan Menggunakan Metode Profile," vol. 1, no. 2, pp. 143-152, 2011.

[12] Y. Malau, "Sistem Pendukung Keputusan Pemilihan Kategori Promosi Produk Menggunakan Metode Profile Matching (Studi Kasus: Minimarket)," MATRIK J. Manajemen, Tek. Inform. dan Rekayasa Komput., vol. 19, no. 2, pp. 339-346, 2020, doi: 10.30812/matrik.v19i2.672.

[13] A. Sindar and A. S. Sitio, "Analisa Big Data Penyebaran Covid-19 Berdasarkan Peta Sebaran dan Peraturan Protokol Dengan Business Intelligence (BI)", vol. 20, no. 3, 11 September 2021, http://dx.doi.org/10.32409/jikstik.20.3.2775. 